Discourse and Communication for Sustainable Education, vol. 12, no. 1, pp. 55-66, 2021

\title{
Discursive Representations of Education for Sustainable Development in Policy Documents by English Medium Instruction Schools in Estonia and Norway
}

\author{
Oleksandr Kapranov \\ Western Norway University of Applied Sciences, Haugesund/Stord, Norway
}

\begin{abstract}
This article introduces and discusses a study that aims at illuminating discursive representations of education for sustainable development (henceforth - ESD) by means of compiling and analysing a corpus of policy documents written by English medium instruction (EMI) secondary schools in Estonia and Norway, respectively. Informed by the constructivist approach (Foucault, 1981), discursive representations of ESD in the study were operationalised as discursive strategies that were employed in naming, referring to, and providing an evaluative perspective to ESD-related topics. In this study, the corpus of policy documents published by EMI secondary schools in Estonia and Norway was collected in order to analyse discursive representations of ESD by means of applying a qualitative content analysis. The results of the analysis indicated that the discursive representations of ESD were similarly construed in policy documents written and communicated by EMI secondary schools in Estonia and Norway. Those findings were further discussed in the article in conjunction with their didactic implications.
\end{abstract}

Key words: discursive representation, education for sustainable development (ESD), English medium instruction (EMI), policy documents, secondary school

\section{Introduction}

Sustainable development is a critical concept that encompasses climate action, sustainability, and quality education (Jodoin \& Singer, 2020) that facilitate human development in a responsible and ecologically sustainable manner (Heasly et al., 2020; Lewis et al., 2019). Sustainable development is pivotal in promoting values and attitudes required for positive social transformation and change (Iliško \& Badjanova, 2014). In recent decades, sustainable development has become an important issue in a variety of educational contexts (Zygmunt, 2016). Given that education is "an important tool in achieving change and sustainable development" (Mochizuki \& Fadeeva, 2010, p. 391; Salite, 2016), education for sustainable development (further in the article - ESD) has been 
recognised as a transformative and meaningful pedagogical activity that is grounded in a particular educational context (Heasly et al., 2020).

Informed by the view of ESD as a transformative and context-bound activity, the present article introduces and discusses a study that is aimed at identifying and analysing discursive representations of ESD in the contexts of English medium instruction (EMI) secondary schools in Estonia and Norway, respectively. This study is commensurate with the focus of the journal Discourse and Communication for Sustainable Education that seeks to examine "policies, theories and practices related to discourse and communication for sustainable education" (Discourse and Communication for Sustainable Education, 2021). In the wake of the journal's ethos, the aim of the study is to identify and classify discursive representations of ESD in policy documents written and communicated by a number of EMI secondary schools in Estonia and Norway. Since the study is focused upon ESD in the EMI context, it appears relevant to specify what EMI stands for. In this study, EMI is defined as the use of the English language to teach academic subjects (other than English itself) in countries or jurisdictions where the first language of the majority of the population is not English (Macaro et al., 2018, p. 37).

From a theoretical perspective, the present study is embedded in the concepts of ESD and discursive representations, respectively. The former is operationalised in the study in accordance with the definition provided by Rieckmann (2018), and Schank and Rieckmann (2019), who posit that ESD is an educational concept that "combines ideas of environmental education, development education, peace education, health education and political education" (Schank \& Rieckmann, 2019, p. 68) in order to empower learners to reflect on how their social, cultural, economic and environmental practices impact upon their lives both locally and globally (Rieckmann, 2018). Such a view of ESD could be exemplified by pedagogical practices of fostering the learners' "attachment and love of nature, as well as an understanding of the interdependency of humans and the natural world" (Heggen, 2016, p. 91) and pedagogical approaches of facilitating the learners' awareness of "global contradictions in terms of human wellbeing and the state of the environment” (Jones, Trier, \& Richards, 2008, p. 341).

Another pivotal concept in the present study involves discursive representations of ESD. The concept of discursive representations is informed by the constructionist approach (Foucault, 1981) that construes discursive representations as linguistic evidence (Alameda-Hernández, 2008) associated with certain social situations and practices, wherein they are produced, exchanged, and co-constructed between the members of a culture (Hall, 1997). In the constructionist approach, discursive representations are thought to be reflective of power relations that occur in cultural, social, and historical contexts (Alameda-Hernández, 2008; Hall, 1997). Arguably, such a view is concomitant with the analytical framework offered by Critical Discourse Analysis (CDA) that foregrounds the concept of power and relates it to discourse, identity, knowledge, and society (Caballero Mengibar, 2015, p. 39). Based upon the CDA framework, a discursive representation could be defined as a discursive strategy that names and refers linguistically to persons, objects, processes, and events as well as characterises their qualities and features, and provides a perspective to discuss them (Khosravinik, Krzyżanowski, \& Wodak, 2012, p. 286). Grounded in the aforementioned view of discursive representations, the study that is further presented and discussed in this article sets out to discover new knowledge about discursive representations of ESD in the corpus of policy documents written and communicated by EMI secondary schools in Estonia and Norway, where English is spoken 
and taught as a foreign language (EFL). Prior to proceeding to the study, however, it appears relevant to provide a review of the prior literature associated with ESD in EFL settings.

\section{ESD in EFL Settings: Literature Review}

In EFL studies, there is a substantial body of research that addresses the issue of ESD in various EFL settings (Al-Jamal \& Al-Omari, 2014; Ganji, Arshadi, \& Mahbubzadeh, 2020; Guanio-Uluru, 2019; Guslyakova, 2020; Jodoin \& Singer, 2020; Mohammadnia \& Moghadam, 2019; Sundh, 2016; Ver Steeg, 2020; Zahoor \& Janjua, 2020). In particular, the research literature problematises ESD in EFL educational settings in terms of EFL learners' and teachers' perceptions of ESD (Ganji, Arshadi, \& Mahbubzadeh, 2020; Guanio-Uluru, 2019; Guslyakova, 2020; Ver Steeg, 2020), environmental themes in EFL textbooks (Al-Jamal \& Al-Omari, 2014; Jodoin \& Singer, 2020; Mohammadnia \& Moghadam, 2019; Zahoor \& Janjua, 2020), and EFL learners' written discourse on ESD-related topics (Sundh, 2016).

EFL learners' and teachers' perceptions of ESD are explored in the studies conducted by Ganji, Arshadi, and Mahbubzadeh (2020), Guanio-Uluru (2019), Guslyakova (2020), and Ver Steeg (2020). Whilst these studies are united by the common research theme associated with the perceptions of ESD in the EFL teaching and learning contexts, they seem to differ in focus. In particular, Ganji, Arshadi, \& Mahbubzadeh (2020) aim at establishing EFL teachers' awareness and understanding of ESD. They have found that whereas EFL teachers in Iran exhibit insufficient awareness of ESD, more than half of the teachers perceive ESD as the protection of natural resources. A possible solution to the insufficient level of awareness of ESD practices is offered by Guanio-Uluru (2019), who indicates that ecocritical aspects of literary texts are facilitative of raising the preservice EFL teachers' awareness of sustainability. Specifically, Guanio-Uluru (2019) argues that lectures on ecocriticism that are followed by debates on the ecocritical literature, as well as the literature circles where pre-service EFL teachers discuss and enact ecocritical reading roles, are considered useful in fostering awareness of sustainability issues. Another aspect of raising EFL students' awareness of ESD is suggested by Guslyakova (2020), who argues that EFL students' eco-consciousness and eco-friendliness can be augmented by working with English-mediated online resources (for instance, YouTube, Facebook, Twitter) that discuss ESD-related topics, such as ecology and environmental issues. Guslyakova (2020) has established that online social platforms are effective means of raising EFL students' environmental awareness. Similarly to Guslyakova (2020), Ver Steeg (2020) suggests that EFL students can greatly benefit from an increased exposure to ESD-related topics. Ver Steeg (2020) posits that EFL students' gains in ESD may be achieved by focusing on the students' relationships to nature. Subsequently, an EFL student's inner world, intersubjectivity, and personal viewpoints regarding the environment are regarded as useful strategies of practicing ESD in the EFL classroom (Ver Steeg, 2020).

The research theme associated with textbooks with environmental and other ESDrelated topics in the EFL teaching and learning is a common denominator for a number of fairly recent studies (Al-Jamal \& Al-Omari, 2014; Jodoin \& Singer, 2020; Mohammadnia \& Moghadam, 2019; Sundh, 2016; Zahoor \& Janjua, 2020). Specifically, AlJamal and Al-Omari (2014) examine EFL textbooks for the presence of key ecological 
concepts. It has been found that only one third of textbooks for EFL learners in secondary schools in Jordanian context involves sensitivity to ecological problems as well as ecological skills development (Al-Jamal \& Al-Omari, 2014). In contrast to EFL textbooks in Jordan, environmental topics and themes have been found to be popular content for English textbooks in Japan (Jodoin \& Singer, 2020). However, the study conducted by Jodoin and Singer (2020) has revealed that there is little thematic interconnectedness among ESD-related topics, images, and texts in EFL textbooks in Japan. Additionally, ESDrelated sustainability competencies appear to be insufficiently represented in EFL textbooks that have been analysed in the study (Jodoin \& Singer, 2020). A similar need to offer a logical interconnectedness among the ESD-related topics in EFL textbooks eventuates from the study conducted by Mohammadnia and Moghadam (2019). Their findings reveal that the topics of sustainability (for instance, life diversity, natural disasters, pollution, recycling, climate change, etc.) that are found in EFL textbooks in Iran should be better interconnected and more evenly distributed (Mohammadnia \& Moghadam, 2019). Similar findings are reported by Zahoor and Janjua (2020), who have examined EFL textbooks in Pakistan. However, in contrast to the findings by Mohammadnia and Moghadam (2019), the discursive representations of environmental issues that are reflected in EFL textbooks in Pakistan bear the mark of anthropocentric worldview and provide an insufficient ecopedagogical perspective (Zahoor \& Janjua, 2020).

The study by Sundh (2016) represents a research theme that explores young EFL learners' written discourse on ESD-related topics. The corpus of the study by Sundh (2016) is comprised of written discourse on the topics of sustainable development produced by young EFL learners from Estonia, Latvia, Lithuania, Russia, and Sweden. By means of examining abstract nouns related to the topics of sustainable development, Sundh (2016) has arrived to the conclusion that young EFL learners are able to reflect on the issue of sustainable development. Notably, all EFL learners in the study conducted by Sundh (2016) managed to write about aspects of sustainable development using the English language. Whilst the participants in the study hail from different linguistic backgrounds, their ESD-related discourse in English could be characterised by several common themes, such as charity, war, and technology (Sundh, 2016, p. 101).

It is evident from the analysis of the prior literature that there are multiple studies that analyse ESD in relation to the EFL teaching and learning contexts. Currently, however, there is insufficient research that addresses ESD-related topics in the context of EMI secondary schools. Furthermore, there are no published studies that compare discursive representations of ESD in policy documents written and communicated by EMI secondary schools in different countries. The present study seeks to generate new knowledge about this under-researched issue.

\section{The Present Study}

The present study aims at identifying and analysing discursive representations of ESD in policy documents written and communicated by EMI secondary schools in Estonia and Norway, respectively. As previously mentioned in the introductory part of this article, EMI is associated with the use of the English language in teaching academic subjects in those countries, where English is not the first language of the majority of the population (Macaro, 2018, p. 15; Macaro et al., 2018, p. 37). Both in Estonia and 
Norway, the majority of the population are not native speakers of English. Estonia and Norway belong to the so-called Expanding Circle of English, i.e. those countries, where English is a foreign language, or EFL (Kachru, 1986). However, both in Estonia and Norway, the English language is prestigious and widely spread due to the internationalisation of higher education (Kibbermann, 2017), the participation of these two countries in a number of international organisations (i.e., NATO, OECD, UNO) where English is one of the official languages, and the substantial presence of multinational corporations that use English as a lingua franca (Beiler, 2020; Raud \& Orehhova, 2017).

The processes of globalisation and internationalisation, which are taken in conjunction with the prestigious status of the English language in Estonia (Raud \& Orehhova, 2017) and Norway (Beiler, 2020), have facilitated the emergence of a number of EMI secondary schools in these two countries (Griffiths, 2013). However, as previously indicated in the article, little is known about discursive representations of ESD in policy documents written and communicated by EMI secondary schools in Estonia and Norway, respectively. In line with Abrahamsen and Aas (2016), school policy documents are operationalised in this study as codified guidelines and explicit expectations associated with the ethos, norms and practices within a particular school that are made publicly available to a variety of stakeholders on the school's Internet website. This study seeks to provide insight into ESD in school policy documents by means of collecting a corpus of policy documents communicated by EMI secondary schools in Estonia and Norway and applying a qualitative content analysis in order to examine the corpus for the presence of discursive representations of ESD. The specific research question in the study is formulated as follows: Are discursive representations of ESD in policy documents written and communicated by EMI secondary schools in Estonia and Norway similar or different?

\section{Corpus}

The corpus was comprised of policy documents (for instance, Mission Statement, Director's Welcome, School Profile, School Philosophy, etc.) written in the English language and communicated online by four EMI secondary schools in Estonia and four EMI secondary schools in Norway, respectively. In total, the corpus of the study consisted of 36 policy documents (total $\mathrm{N}$ of words $=15883$ words) that were readily available as open access material on the Internet. The corpus was processed in the statistical program Statistical Package for Social Sciences (SPSS), version 18.0 (IBM, 2011). The corpus analysis in SPSS (IBM, 2011) yielded the descriptive statistics that were summarised in Table 1.

\section{Table 1}

The Descriptive Statistics of the Corpus

\begin{tabular}{clcc}
\hline N & Descriptive Statistics & EMI in Estonia & EMI in Norway \\
\hline 1 & Total number of texts & 16 & 20 \\
2 & Total number of words & 9688 & 6145 \\
3 & Mean words & 605.5 & 307.2 \\
4 & Standard deviation & 537.6 & 172.7 \\
5 & Minimum & 101 & 62 \\
6 & Maximum & 2122 & 657 \\
\hline
\end{tabular}




\section{Methods and Procedure}

Following Soler, Björkman, and Kuteeva (2018), the methodological approach in the present study involved a summative content analysis that consisted in the identification of themes associated with the discursive representations of ESD-related content. In line with the summative content analysis employed by Soler, Björkman, and Kuteeva (2018), the analysis started with the search of the keywords and key phrases "sustainability", "sustainable education”, "sustainable development”, "ecology", "nature”, and "future". The set of key words to be searched for was adapted from the study that was conducted by Sundh (2016). The keywords and key phrases were searched by means of using the computer program AntConc (Anthony, 2014). First, two files were created by merging the policy documents $(\mathrm{N}=16)$ written by four EMI schools in Estonia (i.e., File 1) and the policy documents $(\mathrm{N}=20)$ by four EMI schools in Norway (File 2), thus making two files in total. Second, the two files were examined for the frequency of the keywords and key phrases in order to identify possible patterns associated with discursive representations of ESD-related themes. Thereafter, the keywords and key phrases were examined manually in their surrounding pieces of discourse to identify potential themes. Following Soler, Björkman, and Kuteeva (2018), the frequent keywords and key phrases were analysed against the background of the discursive clusters that surrounded the keywords and key phrase in the policy documents in order to establish the ESL-related themes in the corpus.

\section{Results and Discussion}

The summative content analysis of the corpus has yielded several themes that are associated with the discursive representations of ESD in policy documents written and communicated online by four EMI secondary schools in Estonia and four respective schools in Norway. These discursive representations are summarised in Table 2 below.

Table 2

Discursive Representations of ESD by EMI Secondary Schools in Estonia and Norway

\begin{tabular}{llcc}
\hline $\mathrm{N}$ & \multicolumn{1}{c}{$\begin{array}{c}\text { Discursive Representations } \\
\text { of ESD }\end{array}$} & $\begin{array}{c}\text { EMI Secondary Schools } \\
\text { in Estonia }\end{array}$ & $\begin{array}{c}\text { EMI Secondary Schools } \\
\text { in Norway }\end{array}$ \\
\hline 1 & Balance & + & + \\
2 & Change & + & + \\
3 & Eco School & + & - \\
4 & Environment and Community & - & + \\
5 & Nature & + & + \\
6 & Peace & + & + \\
7 & Responsibility & + & + \\
8 & Sustainability & + & + \\
\hline
\end{tabular}

The findings that are presented in Table 2 are further discussed from the vantage point of the research question in the study that aims at identifying differences and/or similarities associated with the discursive representations of ESD in the policy documents written and communicated by EMI secondary schools in Estonia and Norway. Let us first discuss those discursive representations that are similar in policy documents by 
EMI secondary schools in Estonia and Norway, i.e. Balance, Change, Nature, Peace, Responsibility, and Sustainability. It should be noted that some of the aforementioned discursive representations, such as Sustainability, Peace, and Change are reported in the prior literature (Guanio-Uluru, 2019; Sundh, 2016). Specifically, it is inferred from the study conducted by Guanio-Uluru $(2019$, p. 13) that the construal of sustainability is routinely mentioned by Norwegian EFL pre-service teachers, who seem to embed it into their oral practices in the EFL classroom. Similarly, the discursive representation Peace in this study appears to be evocative of the research findings reported by Sundh (2016), who has established that the concept of peace is referred to by EFL learners in Estonia and other countries of the Baltic region (e.g., Latvia) in their reflections on sustainable development.

The presence of the similar, moreover, identical discursive representations of ESD is suggestive of the common discursive space that is shared by the EMI secondary schools in Estonia and Norway. In conjunction with this finding, the critical question is associated with the variables that facilitate this common discursive space as far as the representations of ESD are concerned. Arguably, one of the variables could be attributed to the International Baccalaureate (IB) teaching and learning modules offered at all eight schools (four in Estonia, and four in Norway, respectively) whose policy documents are discussed in this study. The ethos of the IB is manifested by its specificity that consists in "crossing disciplinary, cultural and national boundaries" (International Baccalaureate, 2021a), which, in turn, fosters the learner's open-mindedness, balance, and responsibility for the world we live in, given that IB programmes strive to "engage with issues and ideas that have local and global significance" (ibid.). In harmony with the IB's marketing profile, it is, perhaps, not surprising that the discursive representations Balance, Change, Nature, Peace, Responsibility, and Sustainability appear to be commonly construed by the EMI secondary schools in Estonia and Norway. For instance, it is evident from the following Excerpts (1) - (3) that the discursive representation Peace is construed by the EMI secondary school in Estonia (Excerpt 1) and its counterpart in Norway (Excerpt 2) in line with the IB guidelines (Excerpt 3). In (1) and (2), the EMI schools seek to

(1) $[\ldots]$ create a better and more peaceful world through education, provided in a nurturing, student-centered environment where independent learning and personal development are key (International School of Tallinn, 2021).

(2) [...] develop inquiring, knowledgeable and caring young people who help to create a better and more peaceful world through intercultural understanding and respect (International School Telemark, 2021a).

Presumably, the discursive representation Peace in (1) and (2), which is communicated by two EMI schools, has been influenced by the discursive practices associated with ESD which are supported by the IB, e.g.

(3) The International Baccalaureate ${ }^{\circledR}$ aims to develop inquiring, knowledgeable and caring young people who help to create a better and more peaceful world through intercultural understanding and respect (International Baccalaureate, 2021b).

In addition to the marketing guidelines by the IB, another variable that could account for the similarity of discursive representations in the present corpus is associated with the policies of the respective Ministries of Education in Estonia and Norway. For instance, 
as far as the aforementioned discursive representation Peace is concerned, it is stated by the Estonian Ministry of Education and Research that one of its goals in terms of ESD is

(4) [...] to develop learners with the competences to be active citizens in democratic, sustainable, peaceful and just societies and to enable them to engage in decent work (Estonian Ministry of Education and Research, 2018).

Analogously to their counterparts in Estonia, the Norwegian Government emphasises the need for ESD in conjunction with a peaceful future. In particular, the Prime Minister of Norway Erna Solberg indicates that "[...] a sustainable future will depend on peace, stability and good governance" (Solberg, 2016). Arguably, there could be a synergetic effect of the governmental policies in Estonia and Norway, respectively, on the one hand and the IB policies and guidelines on the other hand that results in the construal of identical discursive representations of ESD in the present corpus.

Yet, one more variable is indirectly involved in the creation of the common discursive space associated with the policy documents written and communicated by eight schools in the study. This variable is represented by the general framework of UNESCO's programme on Education for Sustainable Development (2017). The adoption of UNESCO's ESD guidelines by the respective Ministries of Education in Estonia and Norway is evident from the comparison of Excerpt (4) with UNESCO's ESD Goals and Objectives programme (see Excerpt (5) below):

(5) Promote peaceful and inclusive societies for sustainable development, provide access to justice for all and build effective, accountable and inclusive institutions at all levels (UNESCO, 2017, p. 5).

It is very likely that the EMI secondary schools, which are discussed in the present study, have been made aware of UNESCO's ESD guidelines and included them into their school policy documents. Whilst it is beyond the scope of this study to verify this assumption, a detailed comparison of ESD-related school policies in Estonia and Norway with the programme of Education for Sustainable Development (UNESCO, 2017) would be a promising avenue of future research in terms of identifying similar or different discursive representations of ESD.

Apart from the abovementioned common discursive representations of ESD, the results of the corpus analysis have reaved that there are two discursive representations of ESD that are associated with the national differences. These discursive representations are Eco School (EMI secondary schools in Estonia) and Environment and Community (EMI secondary schools in Norway), respectively. In particular, the discursive representation Eco School is exemplified by Excerpt (6), e.g.

(6) Eco Schools is an international movement that brings together schools that actively protect the environment. Our school started participating in the Eco Schools programme in February 2020. The aim of the programme is to help the environment by taking local action one step at a time. Care for one's surroundings provides everybody with a safer, more supportive environment not only physically, but also mentally (Tartu International School, 2021).

Whereas the discursive representation Eco School is specific to the EMI secondary schools in Estonia and not found in the sub-corpus of the Norwegian EMI schools, another country-specific discursive representation of ESD is associated with the EMI in 
Norway, i.e. Environment and Community. This discursive representation is emblematised by the following quote: "We should promote understanding of Environmental and Community issues and encourage students to get involved and make a difference" (International School Telemark, 2021b). To reiterate, only two instances of the country-specific discursive representations of ESD have been found in the corpus, namely Eco School and Environment and Community. The rest of the discursive representations of ESD in the corpus are identical in policy documents written and communicated by EMI schools in Estonia and Norway.

\section{Conclusions}

This article presents a qualitative study that seeks to identify and analyse discursive representations of ESD in school policy documents written and communicated online by eight EMI secondary schools in Estonia ( $\mathrm{N}$ of EMI schools $=4$ ) and Norway ( $\mathrm{N}$ of EMI schools = 4), respectively. By means of applying a summative content analysis, the corpus of school policy documents has been analysed. The results of the analysis have revealed that the discursive representations of ESD are similarly construed in policy documents written and communicated by EMI secondary schools in Estonia and Norway. Specifically, the following discursive representations have been identified in the school policy documents both in Estonia and Norway - Balance, Change, Nature, Peace, Responsibility, and Sustainability. This finding is regarded in the present study as evidence of the common discursive space associated with the representations of ESD that are construed by EMI secondary schools in Estonia and Norway. Presumably, the common discursive space in regard of ESD representations is facilitated by a number of local and international stakeholders. On the international level, the International Baccalaureate and UNESCO could be considered the stakeholders that exert influence on the ESDrelated discursive representations that are found in the present corpus, whereas the respective Ministries of Education are argued to be the local stakeholders that provide frameworks for the discursive representations of ESD.

The aforementioned findings are suggestive of the following didactic implications. First, it appears that ESD-related discourse communicated by EMI schools in Estonia and Norway (and, presumably in other OECD countries) draws from a multi-layered system of input that is provided by national and international stakeholders. Second, ESD-related discourse communicated by EMI schools in Estonia and Norway is reflective of the specificity associated with EMI schools in the sense that they are on the forefront of internationalisation and globalisation that are manifested by using English, the world's international language, and adhering to the principles of International Baccalaureate, a global community of schools and educators. It could be assumed that EMI schools in Estonia and Norway, respectively, exhibit sensitivity to ESD-related discourse which is conveyed by international stakeholders. Due to the international nature of EMI secondary schools, they could offer examples of best practices in terms of applying the principles and practices of ESD in their respective countries.

\section{Acknowledgements}

The author acknowledges the editor and two anonymous reviewers whose input is highly appreciated. 


\section{References}

Abrahamsen, H., \& Aas, M. (2016). School leadership for the future: Heroic or distributed? Translating international discourses in Norwegian policy documents. Journal of Educational Administration and History, 48(1), 68-88.

Alameda-Hernández, Á. (2008). SFL and CDA: Contributions of the analysis of the transitivity system in the study of the discursive construction of national identity (case study: Gibraltar). The Linguistics Journal, 3(3), 160-175.

Al-Jamal, D. A., \& Al-Omari, W. (2014). Thinking green: Analyzing EFL textbooks in light of ecological education themes. Thinking, 5(14), 151-158.

Anthony, L. (2014). AntConc (Version 3.4.3). Tokyo, Japan: Waseda University. www.laurenceanthony.net

Beiler, I. R. (2020). Negotiating multilingual resources in English writing instruction for recent immigrants to Norway. TESOL Quarterly, 54(1), 5-29.

Caballero Mengíbar, A. (2015). Critical discourse analysis in the study of representation, identity politics and power relations: A multi-method approach. Communication \& Society, 28(2), 39-54.

Discourse and Communication for Sustainable Education. (2021). Overview. https://content.sciendo.com/view/journals/dcse/dcse-overview.xml?language=en $\&$ tab_body=overview

Estonian Ministry of Education and Research. (2018). Estonia sets an example with its open and inclusive education system. https://www.hm.ee/en/news/estonia-setsexample-its-open-and-inclusive-education-system

Foucault, M. (1981). The order of discourse. In R. Young (Ed.), Untying the text: A post-structural anthology (pp. 48-78). Boston: Routledge \& Kegan Paul.

Ganji, M., Arshadi, E. K., \& Mahbubzadeh, S. (2020). Sustainable development from the viewpoint of Iranian English teachers: Practicing what they do not preach. Journal of Teacher Education for Sustainability, 22(1), 140-164.

Griffiths, E. (2013). English as a medium of instruction in higher education institutions in Norway: A critical exploratory study of lecturers' perspectives and practices. (Unpublished doctoral dissertation). University of Exeter, Exeter (the UK). http://hdl.handle.net/10871/14538

Guanio-Uluru, L. (2019). Education for sustainability: Developing ecocritical literature circles in the student teacher classroom. Discourse and Communication for Sustainable Education, 10(1), 5-19.

Guslyakova, A. (2020). Young people's eco-consciousness evolution through the prism of the new media discourse perception and interaction in the course of L1 acquisition. In L. Gómez Chova, A. López Martínez, \& I. C. Torres (Eds.), Proceedings of INTED2020 Conference $2^{\text {nd }} 4^{\text {th }}$ March 2020, Valencia, Spain (pp. 9014-9018). Valencia: IATED.

Hall, S. (1997). The work of representation. In S. Hall (Ed.), Representation: Cultural representations and signifying practices (pp. 13-74). London: Sage and The Open University.

Heasly, B., Lindner, J., Iliško, D., \& Salīte, I. (2020). From initiatives, to insights, to implementation of the sustainability and securitability agenda for 2030. Discourse and Communication for Sustainable Education, 11(1), 1-4.

Heggen, M. P. (2016). Education for sustainable development in Norway. In J. SirajBlatchford, C. Mogharreban, \& E. Park (Eds.), International research on education for sustainable development in early childhood (pp. 91-102). Cham: Springer. 
IBM. (2011). IBM SPSS statistics for Windows, version 18.0. New York: IBM Corp. Iliško, D., \& Badjanova, Y. (2014). A case study of ESD implementation: Signs of sustainable leadership. Discourse and Communication for Sustainable Education, $5(1), 38-48$.

International Baccalaureate. (2021a). The IB learner profile. https://www.ibo.org/ benefits/learner-profile/

International Baccalaureate. (2021b). Mission. https://www.ibo.org/about-the-ib/mission/ International School of Bergen. (2021). The Mission. https://isbergen.no/about/themission/

International School of Estonia. (2021). Our Mission. https://ise.edu.ee/about-2/missionvision/

International School of Tallinn. (2021). Director's Welcome. https://ist.ee/directorswelcome/

International School Telemark. (2021a). IB \& IB Learner Profile. http://istelemark.no/ nb/learning/ib-ib-learner-profile/

International School Telemark. (2021b). Mission and Philosophy. http://istelemark.no/ learning/key-documents/

Jodoin, J., \& Singer, J. (2020). Mainstreaming education for sustainable development in English as a foreign language: An analysis of the image-text interplay found in EFL textbooks in Japanese higher education. In W. L. Filho, A. L. Salvia, R. W. Pretorius, L. L. Brandli, E. Manolas, F. Alves, U. Azeiteiro, J. Rogers, C. Shiel, \& A. Do Paco (Eds.), Universities as Living Labs for Sustainable Development (pp. 545565). Cham: Springer.

Jones, P., Trier, C. J., \& Richards, J. P. (2008). Embedding education for sustainable development in higher education: A case study examining common challenges and opportunities for undergraduate programmes. International Journal of Educational Research, 47(6), 341-350.

Kachru, B. B. (1986). The alchemy of English: The spread, functions, and models of non-native englishes. Chicago: University of Illinois Press.

Khosravinik, M., Krzyżanowski, M., \& Wodak, R. (2012). Dynamics of representation in discourse: Immigrants in the British press. In M. Messer, R. Schroeder, \& R. Wodak (Eds.), Migrations: Interdisciplinary perspectives (pp. 283-295). Vienna: Springer.

Kibbermann, K. (2017). Responses to the internationalisation of higher education in language policies of Estonia and Latvia. Journal of Estonian and Finno-Ugric Linguistics, 8(1), 97-113.

Lewis, R. A., Kenerson, M. J., Sorrentino, C., \& Rowse, T. H. (2019). Experiencing sustainability education: Insights from a living and learning programme. Journal of Education for Sustainable Development, 13(1), 24-44.

Macaro, E. (2018). English medium instruction. Oxford: Oxford University Press.

Macaro, E., Curle, S., Pun, J., An, J., \& Dearden, J. (2018). A systematic review of English medium instruction in higher education. Language Teaching, 51(1), 36-76.

Mochizuki, Y., \& Fadeeva, Z. (2010). Competences for sustainable development and sustainability: Significance and challenges for ESD. International Journal of Sustainability in Higher Education, 11(4), 391-403.

Mohammadnia, Z., \& Moghadam, F. D. (2019). Textbooks as resources for education for sustainable development: A content analysis. Journal of Teacher Education for Sustainability, 21(1), 103-114. 
Raud, N., \& Orehhova, O. (2017). In-service training of teachers of English as a foreign language in Estonia: Mapping of trends and opportunities. Problems of Education in the $21^{\text {st }}$ Century, 75(2), 194-203.

Rieckmann, M. (2018). Key themes in Education for Sustainable Development. In A. Leicht, J. Heiss, \& W. J. Byun (Eds.), Issues and trends in education for sustainable development (pp. 61-85). Paris: UNESCO.

Salite, I. (2016). Searching for sustainability in teacher education and educational research: Experiences from the Baltic and Black Sea Circle Consortium for educational research. Discourse and Communication for Sustainable Education, 6(1), 21-29.

Schank, C., \& Rieckmann, M. (2019). Socio-economically substantiated education for sustainable development: Development of competencies and value orientations between individual responsibility and structural transformation. Journal of Education for Sustainable Development, 13(1), 67-91.

Solberg, E. (2016). Fullerton lecture: The global goals - a roadmap to a sustainable, fair and more peaceful future. https://www.regjeringen.no/no/aktuelt/the-global-goalsa-roadmap-to-a-sustainable-fair-and-more-peaceful-future/id2483522/

Soler, J., Björkman, B., \& Kuteeva, M. (2018). University language policies in Estonia and Sweden: Exploring the interplay between English and national languages in higher education. Journal of Multilingual and Multicultural Development, 39(1), 29-43.

Sundh, S. (2016). A corpus of young learners' English in the Baltic region - texts for studies on sustainable development. Discourse and Communication for Sustainable Education, 7(2), 92-104.

Tartu International School. (2021). Eco schools programme. http://istartu.ee/eco-schoolsprogramme/

UNESCO. (2017). Education for Sustainable Development Goals: Learning objectives. Paris: UNESCO. https://www.unesco.de/sites/default/files/2018-08/unesco_ education_for_sustainable_development_goals.pdf

Ver Steeg, J. (2020). Rethinking human/nature ontology in the EFL classroom as a focus of education for sustainable development. In T. Issa, T. Issa, T. B. Issa, \& P. Isaias (Eds.), Sustainability awareness and green information technologies (pp. 5369). Cham: Springer.

Zahoor, M., \& Janjua, F. (2020). Green contents in English language textbooks in Pakistan: An ecolinguistic and ecopedagogical appraisal. British Educational Research Journal, 46(2), 321-338.

Zygmunt, T. (2016). Language education for sustainable development. Discourse and Communication for Sustainable Education, 7(1), 112-124.

Correspondence concerning this paper should be addressed to Dr. Oleksandr Kapranov, Western Norway University of Applied Sciences, Campus Haugesund/Stord, Bjørnsonsgate 45, 5528 Haugesund, Norway. Email: Oleksandr.Kapranov@hvl.no, oleksandr.kapranov@gmail.com 